\title{
Electropolymerization of Starburst Triarylamines and Their Application to Electrochromism and Electroluminescence
}

\author{
Meng-Yen Chou, ${ }^{\dagger}$ Man-kit Leung, ${ }^{*,+, \neq}$ Yuhlong Oliver Su, ${ }^{*}, l l$ Chang Ling Chiang, ${ }^{\dagger}$ \\ Chang-Chih Lin, ${ }^{\dagger}$ J un-Hong Liu, ${ }^{\dagger}$ Chin-Kuei Kuo, ${ }^{\dagger}$ and Chung-Yuan Mou ${ }^{\dagger, \S}$ \\ Department of Chemistry, Institute of Polymer Science and Engineering, and \\ Center for Condensed Matter Sciences, National Taiwan University, Taipei, Taiwan 106, \\ Republic of China, and Department of Chemistry, National Chi Nan University, \\ Nantou, Taiwan 545, Republic of China.
}

Received August 7, 2003. Revised Manuscript Received December 6, 2003

\begin{abstract}
Starburst triarylamines $\mathbf{2}$ and $\mathbf{3}$ were el ectropolymerized to form electrochromic thin films. Film from 2 showed intense absorption at $372 \mathrm{~nm}$ before voltage was applied. There were two absorption bands at $496 \mathrm{~nm}$ and 1000-2000 nm at $0.3 \mathrm{~V}$, and a broad band, which peaked at $807 \mathrm{~nm}$ at $0.6 \mathrm{~V}$. Film from 3 showed intense absorption at $372 \mathrm{~nm}$ before voltage was applied. There were two absorption bands at $498 \mathrm{~nm}$ and $1000-2000 \mathrm{~nm}$ at $0.3 \mathrm{~V}$, and a broad band, which peaked at $890 \mathrm{~nm}$ at $0.7 \mathrm{~V}$. The switching time studies revealed that thin film from 2 would require $3 \mathrm{~s}$ at $0.46 \mathrm{~V}$ for switching absorbance at $1600 \mathrm{~nm}$ and $1 \mathrm{~s}$ for bleaching. It would also require $4 \mathrm{~s}$ at $0.66 \mathrm{~V}$ for col oration at $800 \mathrm{~nm}$ and $2 \mathrm{~s}$ for bleaching. On the other hand, thin film from 3 would require $3 \mathrm{~s}$ at $0.46 \mathrm{~V}$ for switching absorbance at $1500 \mathrm{~nm}$ and $1 \mathrm{~s}$ for bleaching. It would also require $3.3 \mathrm{~s}$ at $0.76 \mathrm{~V}$ for switching absorbance at $900 \mathrm{~nm}$ and $1.5 \mathrm{~s}$ for bleaching. Electropolymerized thin films of $\mathbf{2}$ and $\mathbf{3}$ were also used as the surface modification layers to modify the surface of ITO for polymeric light emitting diode (PLED). To evaluate the performance of the modification layer, we selected a device of ITO/modification layer/PVK-Alq ${ }_{3}$-coumarin 6/metal electrode as the standard for comparison. We discovered that co-electropolymerization of the triarylamines $\mathbf{2}$ or $\mathbf{3}$ with poly(vinylcarbazole) (PVK) on ITO greatly reduces the turn-on voltage of the PLED devices and their performance is comparable to that of the commercially available PEDOT.
\end{abstract}

\section{Introduction}

During the last few decades, polymeric optoelectronic devices based on conjugated or nonconjugated polymers have become extremely important areas of study. ${ }^{1}$ To fabricate an optoel ectronic device, the polymer is usually prepared as a uniform thin film deposited onto an ITO electrode by spin-casting or dip-coating methods. This

* Authors to whom correspondence should be addressed. M.-k.L. e-mail: mkleung@itu.edu.tw.

† Department of Chemistry, National Taiwan University.

‡ Institute of Polymer Science and Engineering, National Taiwan University.

$\S$ Center for Condensed Matter Sciences, National Taiwan University.

"Department of Chemistry, National Chi Nan University.

(1) (a) Sönmez, G.; Schwendeman, I.; Schottland, P.; Zong, K.; Reynolds, J . R. Macromolecules 2003, 36, 639. (b) Huang, J .; Virji, S.; Weiller, B. H.; Kaner, R. B. J . Am. Chem. Soc. 2003, 125, 314. (c) Ho, H. A.; Leclerc, M. J . Am. Chem. Soc. 2003, 125, 4412. (d) Ishihara, M.; Okumoto, K.; Shirota, Y. Chem. Lett. 2003, 32, 162. (e) Okumoto, K.; Shirota, Y. Chem. Mater. 2003, 15, 699. (f) Bernier, S.; Garreau, S.; Béra-Abérem, M.; Gravel, C.; Leclerc, M. J . Am. Chem. Soc. 2002 124, 12463. (g) Goto, H.; Yashima, E. J. Am. Chem. Soc. 2002, 124, 7943. (h) Eldo, J .; Ajayaghosh, A. Chem. Mater. 2002, 14, 410. (i) Rosseinsky D. R.; Mortimer R. J . Adv. Mater. 2001, 13, 783. (j) Liu, B.; Yu, W.-L.; Lai, Y.-H.; Huang, W. Chem. Mater. 2001, 13, 1984. (k) Kuebler, S. M.; Denning, R. G.; Anderson, H. L. J . Am. Chem. Soc. 2000, 122, 339. (I) Neef, C. J .; Brotherston, I. D.; Ferraris, J . P. Chem. Mater. 1999, 11, 1957. (m) Kraft, A.; Grimsdale, A. C.; Holmes, A. B. Angew. Chem., Int. Ed. Engl. 1998, 37, 402. (n) Monk, P. M. S.; Mortimer, R. J .; Rosseinsky, D. R. Electrochromism: Fundamentals and Applications; VCH: Weinheim, 1995. requires good solubility of the polymer in an appropriate solvent. Because of the low solubility of conjugated polymers, their optoelectronic applications are sometimes limited. To enhance the solubility of the conjugated polymers, alkyl or alkoxyl side chains were introduced. ${ }^{2}$ On the other hand, direct film formation on ITO glass by thermal treatment, ${ }^{3}$ self-assembly methods, ${ }^{4}$ or electropolymerization ${ }^{4}$ provides other options to avoid the solubility problem. The family of triarylamines attracts us because of their excellent electronic properties. ${ }^{6}$ Although it has long been known that triphenylamine is electrochemically active and would dimerize to give $\mathbf{1}$, compound $\mathbf{1}$ and higher linear homologues were found to be sluggish toward electro-

(2) (a) Braun, D.; Heeger A. J . Appl. Phys. Lett. 1991, 58, 1982. (b) Ohmori, Y.; Uchida, M.; Muro, K.; Y oshino, K.J pn. J . Appl. Phys. 1991 30, L1941. (c) Grice, A. W.; Bradley, D. D. C.; Bernius, M. T.; Inbasekaran, M.; Wu, W. W.; Woo, E. P. Appl. Phys. Lett. 1998, 73, 629.

(3) Burroughes, J. H.; Bradley, D. D. C.; Brown, A. R.; Marks, R. N.; Mackay, K.; Friend, R. H.; Burns, P. L.; Holmes, A. B. Nature 1990, 347, 539.

(4) (a) Flink, S.; van Veggel, F. C. J. M.; Reinhoudt, D. N. Adv Mater. 2000, 12, 1315. (b) Bliznyuk, V.; Ruhstaller, B.; Brock, P. J . Scherf, U.; Carter, S. A. Adv. Mater. 1999, 11, 1257. (c) Ho, P. K. H.; Granström, M.; Friend, R. H.; Greenham, N. C. Adv. Mater. 1998, 10, 769. (d) Horowitz, G. Belannoy, P.; Bouchriha, H.; Deloffre, F.; Fave, J .-L.; Garnier, F.; Hajlaoui, R.; Heyman, M.; Kouki, F.; Valat, P.; Wintgens, V.; Y assar, A. Adv. Mater. 1994, 6, 752. (e) Geiger, F .; Stoldt M.; Schweizer, H.; Bäuerle, P.; Umbach, E. Adv. Mater. 1993, 5, 922 
polymerization. ${ }^{7}$ These results steer us to search for other triarylamine derivatives ${ }^{8,9}$ that could be effectively polymerized by electrochemical methods. Starburst triarylamine derivatives have played an important role in recent el ectroluminescence applications and have been widely explored. ${ }^{10}$ This family intrigues us because they have higher branching numbers and are supposed to polymerize more effectively than the linear family from the statistical point of view. Herein we report the el ectropolymerization of 3-fold starburst triarylamines $\mathbf{2}$ and $\mathbf{3}$ and their applications to electrochromism and el ectroluminscence.

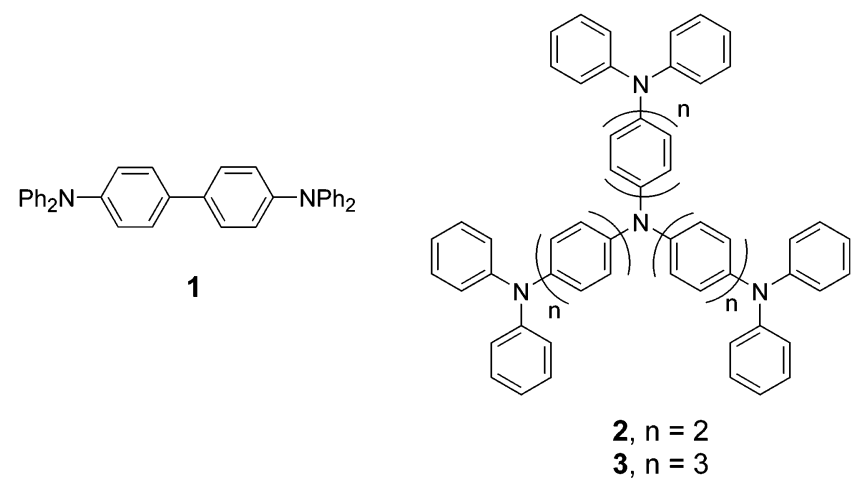

Results and Discussion

Synthesis and Characterization. The synthesis is shown in Schemes 1 and 2. We adopt Suzuki coupling ${ }^{11}$ as a key method for building up the 3-fold skeleton. Bromination of triphenylamine in DMF/toluene led to 4 as the core unit.12 The sidearm was prepared from a two-step synthetic sequence of Buchwald-Hartwig amination, ${ }^{13}$ followed by boronic acid or ester formation. Respectively reacting 1,4-dibromobenzene and 4,4'dibromobiphenyl with $\mathrm{Ph}_{2} \mathrm{NH}$ in the presence of palladium catalysts gave $\mathbf{5}$ and $\mathbf{6}$ in moderate yiel d. In the synthesis of $\mathbf{6}$, a small amount of over-amination product was obtained. Fortunately, the desired 6 was

(5) (a) Komaba, S.; F ujihana K.; Kaneko, N., Osaka, T. Chem. Lett. 1995, 10, 923. (b) Zhang, F.; Petr, A.; Kirbach, U.; Dunsch, L.J . Mater Chem. 2003, 13, 265. (c) Roncali, J.J. Mater. Chem. 1999, 9, 1875. (d) Komaba, S.; Amano, A.; Osaka, T. J . Electroanal. Chem. 1997, 430, 97. (e) Martin, C. R. Acc. Chem. Res. 1995, 28, 61. (f) Favre, C.; Abello, L.; Delabouglise, D. Adv. Mater. 1997, 9, 722. (g) Onishi, K.; Advincula, R. C. Polym. Prepr. (Am. Chem. Soc., Div. Polym. Chem.) 2003, 44 1167. (h) Xia, C.; Advincula, R. C. Chem. Mater. 2001, 13, 1682. (i) Onishi, K.; Advincula, R. C. Polym. Mater. Sci. Eng. 2002, 86, 259.

(6) (a) Loy, D. E.; Koene, B. E.; Thompson, M. E. Adv. Fund. Mater. 2002, 12, 245. (b) Shirota, Y. J . Mater. Chem. 2000, 10, 1. (c) Tanaka H.; Tokito, S.; Taga, Y.; Okada, A. Chem. Commun. 1996, 2175. (d) Adachi, C.; Nagai, K.; Tamoto, N. Appl. Phys. Lett. 1996, 66, 2679.

(7) Mizoguchi, T.; Adams, R. N. J . Am. Chem. Soc. 1962, 84, 2058.

(8) (a) Lambert, C.; Nöll, G. Synth. Met. 2003, 139, 57. (b) Petr, A.; Kvarnström, C.; Dunsch, L.; I vaska, A. Synth. Met. 2000, 108, 245.

(9) Leung, M.-k.; Chou, M.-Y.; Su, Y. O.; Chiang, C.-L.; Chen, H.L.; Yang, C. F., Yang, C.-C., Lin, C.-C.; Chen, H.-T. Org. Lett. 2003, 5, 839.

(10) (a) Ranasinghe, M. I.; Varnavski, O. P.; Pawlas, J .; Hauck, S. I.; Louie, J .; Hartwig, J . F.; Goodson, T., III J . Am. Chem. Soc. 2002, 124, 6520. (b) Katsuma, K.; Shirota, Y. Adv. Mater. 1998, 10, 223. (c) Kuwabara, Y.; Ogawa, H.; Inada, H.; Noma, N.; Shirota, Y. Adv. Mater. 1994, 6, 677. (d) Shirota, Y.; Kobata, T.; Noma, N. Chem. Lett. 1989, 1145. (e) Thelakkat, M.: Schmidt, H.-W. Adv. Mater. 1998, 10, 219.

(11) For review, see Miyaura, N.; Suzuki, A. Chem. Rev. 1995, 95, 2457.

(12) Reynolds, D. W.; Lorenz, K. T.; Chiou, H.-S.; Bellville, D. J .; Pabon, R. A.; Bauld, N. L. J . Am. Chem. Soc. 1987, 109, 4960.

(13) (a) Hartwig, J. F. Acc. Chem. Res. 1998, 31, 852. (b) Wolfe, J. P.; Wagaw, S.; Marcoux, J .-F.; Buchwald, S. L. Acc. Chem. Res. 1998, $31,805$.

\section{Scheme 1}

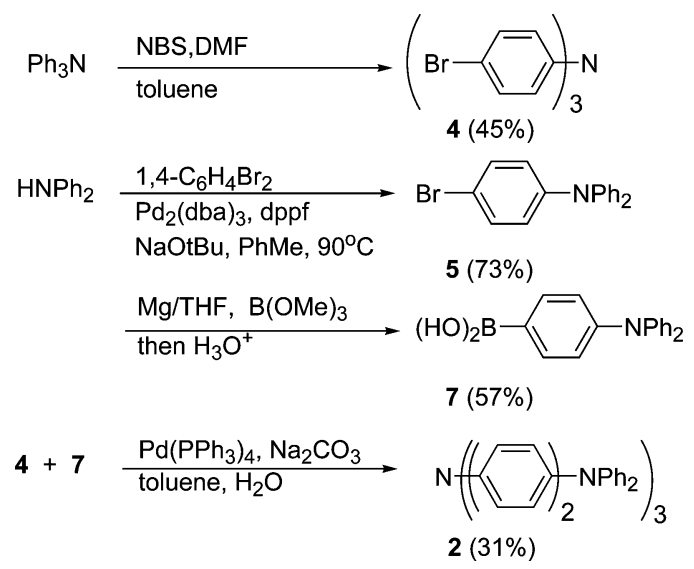

Scheme 2

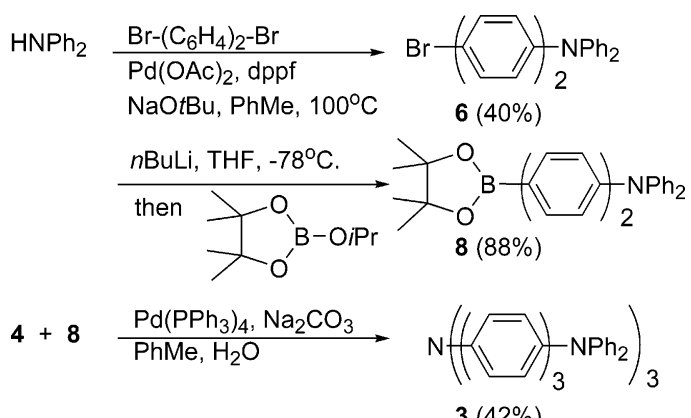

$3(42 \%)$

easily purified through liquid chromatography on silica gel. Treatment of $\mathbf{5}$ with magnesium, followed by reaction with $\mathrm{B}(\mathrm{OMe})_{3}$ and hydrolysis led to 7 . The boronic acid was then coupled with the core unit $\mathbf{4}$ to give starburst $\mathbf{2}$ as a colorless solid. By adopting a similar strategy, a higher homologue $\mathbf{3}$ was prepared from $\mathbf{4}$ and $\mathbf{8}$ in acceptable yield.

Both compounds $\mathbf{2}$ and $\mathbf{3}$ are mol ecular glassy materials with high glass-transition temperature $\left(T_{g}\right)^{6,10,14}$ Differential scanning calorimetric analysis showed that 2 and 3 have $T_{g}$ at 143 and $160{ }^{\circ} \mathrm{C}$, respectively. In addition, both compounds show high thermal stability, and thet have $5 \%$ weight loss temperatures at 400 and $554{ }^{\circ} \mathrm{C}$, respectively.

The oxidative electrochemical behavior of $\mathbf{2}$ and $\mathbf{3}$ (1 $\mathrm{mM}$ ) was examined by cyclic voltammetry (CV) on Pt electrodes in $\mathrm{CH}_{2} \mathrm{Cl}_{2}$ with $(\mathrm{Bu})_{4} \mathrm{NClO}_{4}$ as the supporting electrolyte and $\mathrm{Ag} / \mathrm{AgCl}$ (saturated) as the reference electrode. The potential values are reported with respect to ferrocene standard.

Starburst triarylamine $\mathbf{2}$ showed four stepwise-oxidation waves, which peaked at $0.25,0.46,0.58$, and $0.7 \mathrm{~V}$ in the first CV scan (Figure 1a). Perhaps due to farther distances and weaker interactions between the amino units, 3 showed a shoulder at $0.34 \mathrm{~V}$ and a broad wave at $0.48 \mathrm{~V}$ in the first CV scan. As shown in the CV diagram of $\mathbf{3}$ (Figure $1 \mathrm{~b}$ ), the peak current for the first shoulder is relatively small in comparison to that of the second wave, suggesting a multistep oxidation merged in the second wave. In contrast to the linear family, ${ }^{9}$ irreversible oxidation of $\mathbf{2}$ and $\mathbf{3}$ were observed with film growing effectively on the el ectrode at low concentration

(14) (a) Tokito, S.; Tanaka, H.; Noda, K.; Okada, A.; Taga, Y. Appl. Phys. Lett. 1997, 70, 1929. (b) Tokito, S.; Tanaka, H.; Okada, A.; Taga, Y. Appl. Phys. Lett. 1996, 69, 878. 
(a)

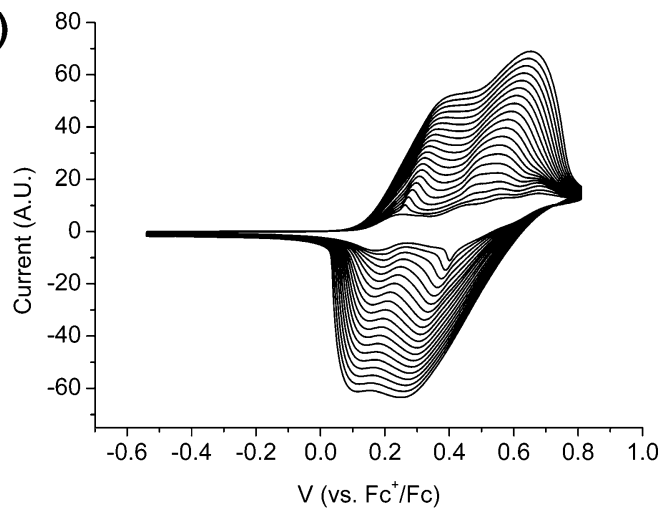

(b)

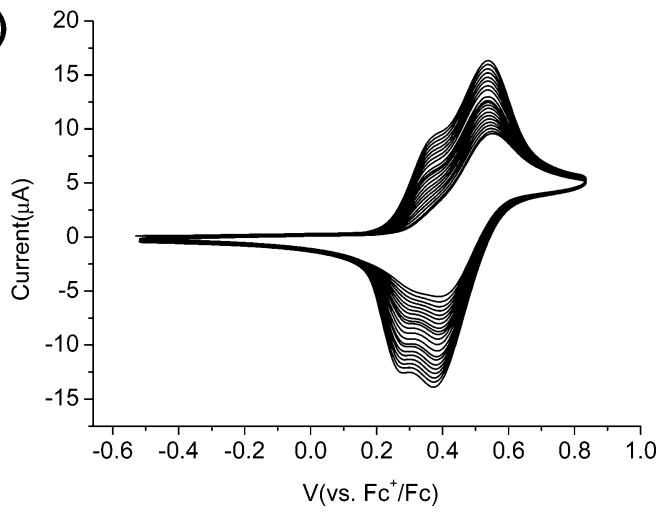

Figure 1. Cyclic voltammogram of (a) compound 2 (1 mM), and (b) compound $3(1 \mathrm{mM})$ in $\mathrm{CH}_{2} \mathrm{Cl}_{2}$ with $(\mathrm{Bu})_{4} \mathrm{NClO}_{4}(0.1$ $\mathrm{M})$ as the supporting electrolyte.

(1 $\mathrm{mM}$ ). After repeated scans for film growing, the original four-wave oxidation of $\mathbf{2}$ disappeared. Instead of these, two broad oxidation waves with $E_{1 / 2}$ showed up at 0.25 and $0.45 \mathrm{~V}$. These $E_{1 / 2}$ values are close to the $E_{1 / 2}$ values of 1,9 indicating the formation of the $4,4^{\prime}$ diaminobi phenyl linkages. Similar observations of film growing were also obtained on oxidation of $\mathbf{3}$. Repeated scans for several cycles led to thin film of $\mathbf{3}$ with two oxidation waves, which slightly shifted to 0.3 and 0.45 $\mathrm{V}$. More interesting is the fact that the first oxidation wave of $\mathbf{3}$ did not lead to el ectrochemical polymerization. We tentatively assigned the first wave to the oxidation of the central triarylamino core, and this resulted in an inert radical cation localized at the central part of the starburst skeleton. Further oxidation occurred at the terminal triarylamine units, which resulted in multistep oxidation and electrochemical polymerization.

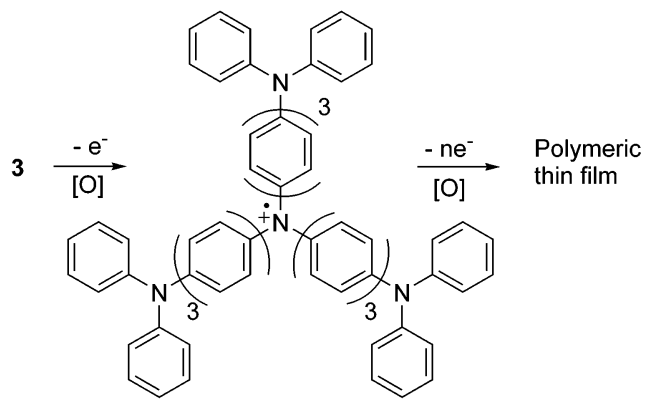

Noteworthy to mention is the effect arising from the supporting electrolyte. For reasons unknown, the rate of film growth in a solution of $(\mathrm{Bu})_{4} \mathrm{NPF}_{4}$ is slower than the rate in a solution of $(\mathrm{Bu})_{4} \mathrm{NClO}_{4}$. However, this
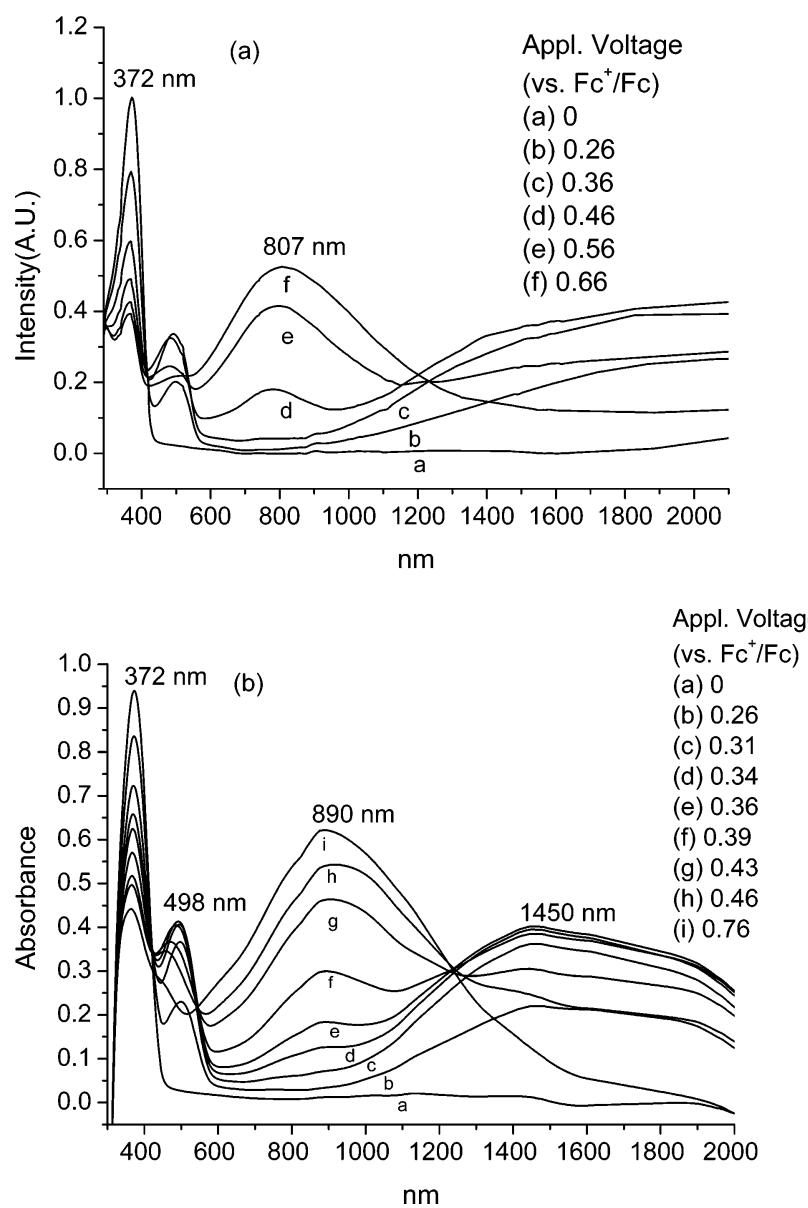

Figure 2. Electrochromic behavior of polymeric thin films from (a) 2, and (b) 3, at electrical potential vs $\mathrm{Fc}^{+} / \mathrm{Fc}$ as the reference in $\mathrm{CH}_{2} \mathrm{Cl}_{2}$ with $(\mathrm{Bu})_{4} \mathrm{NClO}_{4}(0.1 \mathrm{M})$ as the supporting el ectrolyte.

provides us with a good option to control the thickness of the film. In some optoel ectronic applications, the film thickness of the polymer layer is important and necessarily controlled at around 50-100 nm.

Electrochromic Properties. Electrochromism of thin films from $\mathbf{2}$ and $\mathbf{3}$ was examined by direct electrochemical deposition of the polymers onto ITO glass electrodes, and their electrochromic absorption spectra were monitored by a UV-Vis-NIR spectrometer at different voltages (Figure 2). The electrochemical experimental conditions were identical to those used for CV analysis. The applied voltages reported herein were referenced to the ferrocene standard. The scans for spectroel ectrochemistry were made anodically, from 0.2 to $0.8 \mathrm{~V}$, and there was a 2-min equilibration before each spectral scan was applied to mininize transient effect. The results are shown as a series of UV-Vis absorbance spectra correlated to film potential.

Before electrical potential was applied, the slightly yellowish polymeric films from $\mathbf{2}$ showed an intense absorption at $372 \mathrm{~nm}$ (Figure 2a). By setting the potential to $0.3 \mathrm{~V}$, the film turnedorange and gave new absorption bands in Vis and NIR regions. They ranged from 450 to 600 and from 1000 to $2000 \mathrm{~nm}$, respectively. These absorptions are tentatively attributed to the formation of the aminyl radical cations. Because of the intervalence charge transfer (IVCT) interactions with the adjacent amino groups, the aminyl radical cations usually show absorption in the NIR region. The IVCT 

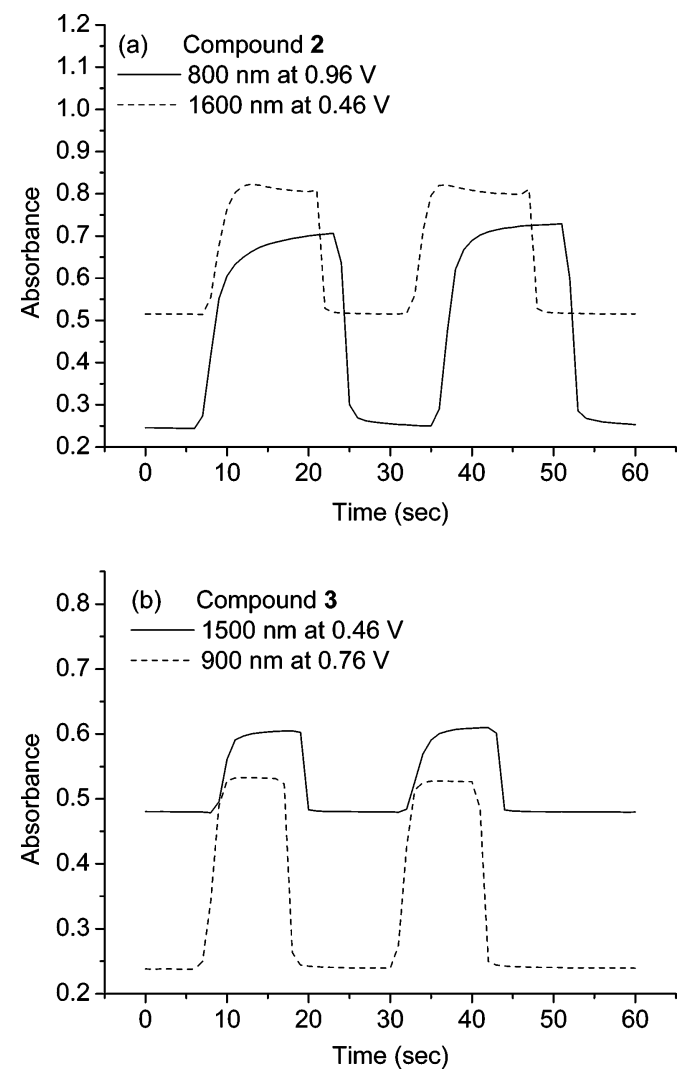

Figure 3. Potential step absorptometry of (a) the polymeric film of $\mathbf{2}$ at 800 and $1600 \mathrm{~nm}$, and (b) the polymeric film of $\mathbf{3}$ at 900 and $1500 \mathrm{~nm}$ in $\mathrm{CH}_{2} \mathrm{Cl}_{2}$ with $(\mathrm{Bu})_{4} \mathrm{NClO}_{4}(0.1 \mathrm{M})$ as the supporting electrolyte.

phenomenon of the family of triarylamines has been explored by many research teams. ${ }^{15} \mathrm{~F}$ urther increasing the applied potential to $0.6 \mathrm{~V}$ led to a deep blue film with a broad absorption band, which peaked at $807 \mathrm{~nm}$, and covered the visible and NIR regions, which ranged from 400 to $1200 \mathrm{~nm}$.

Thin films from 3 showed similar electrochromic behavior (Figure 2b). Before electrical potential was applied, the polymeric film from $\mathbf{3}$ showed intense absorption in the UV region, and peaked at $372 \mathrm{~nm}$. By setting the potential to $0.3 \mathrm{~V}$, the film gave new absorption bands in the $\mathrm{Vis}$ and NIR regions, which ranged from 450 to 600 and 1000 to $2000 \mathrm{~nm}$, respectively. Further increasing the applied potential to 0.7 $\checkmark$ led to a broad absorption band, which peaked at 890 $\mathrm{nm}$, and covered the visible and NIR regions ranging from 400 to $1500 \mathrm{~nm}$.

The color switching times were estimated by applying a potential step, and the absorbance profiles were followed (Figure 3 ). The switching time was defined as the time that required to reach $90 \%$ of the full change in absorbance after switching potential. Thin films from 2 would require $3 \mathrm{~s}$ at $0.46 \mathrm{~V}$ for switching absorbance at $1600 \mathrm{~nm}$ and $1 \mathrm{~s}$ for bleaching. When the potential was set at $0.66 \mathrm{~V}$, thin films from $\mathbf{2}$ would require al most $4 \mathrm{~s}$ for coloration at $800 \mathrm{~nm}$ and $2 \mathrm{~s}$ for bleaching. On the other hand, thin films from 3 would require $3 \mathrm{~s}$ at

(15) (a) Nelsen, S. F.; Pladziewicz, J . R. Acc. Chem. Res. 2002, 35 , 247. (b) Lambert, C.; Nöll, G. Chem. Eur. J . 2002, 8, 3467. (c) Lambert, C.; Nöll, G. Angew. Chem., Int. Ed. 1998, 37, 2107. (d) Lambert, C.; Nöll, G. J . Am. Chem. Soc. 1999, 121, 8434. (e) Hauck, S. I.; Lakshmi, K. V.; Hartwig, J . F. Org. Lett. 1999, 1, 2057.

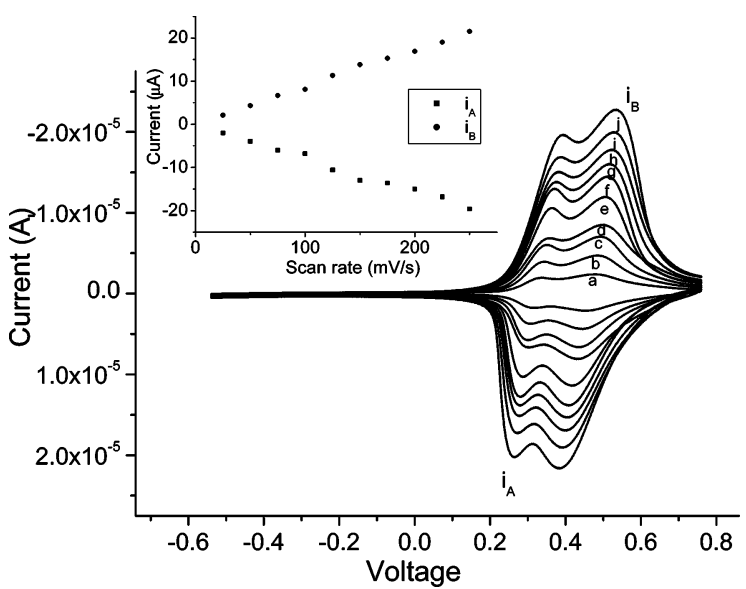

Figure 4. Scan-rate-dependent cyclic voltammograms of the thin film from electropolymerization of $\mathbf{3}$ at 25 (a), 50 (b), 75 (c), 100 (d), 125 (e), 150 (f), 175 (g), 200 (h), 225 (i), and 250 (j) $\mathrm{mV} / \mathrm{s}$ in $\mathrm{CH}_{2} \mathrm{Cl}_{2}$ with $(\mathrm{Bu})_{4} \mathrm{NClO}_{4}(0.1 \mathrm{M})$ as the supporting electrolyte. Potential vs $\mathrm{FC}^{+} / \mathrm{Fc}$ was used as the reference.

$0.46 \mathrm{~V}$ for switching absorbance at $1500 \mathrm{~nm}$ and $1 \mathrm{~s}$ for bleaching. When the potential was set at $0.76 \mathrm{~V}$, thin films from 3 would require $3.3 \mathrm{~s}$ for switching absorbance at $900 \mathrm{~nm}$ and $1.5 \mathrm{~s}$ for bleaching.

The switching times shown above are somewhat slower than the typical switching time of $1-2 \mathrm{~s}$ for electrochromic polymer films. This may be due to slow ion permeation or relatively high internal resistance in comparison to those of conducting polymers such as polythiophene or polypyrrole derivatives. ${ }^{16}$ However, due to its absorption character in the NIR region, we expected that this type of electrochromic polymer would be useful for the purpose of heat absorption.

To further understand the properties of the electropolymerized films, we selected the film from electrodeposition of $\mathbf{3}$ for scan rate dependent study. The cyclic voltammograms are shown in Figure 4. Scans were run at $25,50,75,100,125,150,175,200,225$, and $250 \mathrm{mV} / \mathrm{s}$, respectively. The hysteresis between the oxidative and reductive peaks increases with the scan rate, from $\Delta \mathrm{E}_{\mathrm{p}}=0.017 \mathrm{~V}$ at $25 \mathrm{mV} / \mathrm{s}$ to $\Delta \mathrm{E}_{\mathrm{p}}=0.13 \mathrm{~V}$ at $250 \mathrm{mV} / \mathrm{s}$ for the first wave, and from $\Delta \mathrm{E}_{\mathrm{p}}=0.019 \mathrm{~V}$ at $25 \mathrm{mV} / \mathrm{s}$ to $\Delta \mathrm{E}_{\mathrm{p}}=0.15 \mathrm{~V}$ at $250 \mathrm{mV} / \mathrm{s}$ for the second wave. This increasing hysteresis indicates a non-Nernstian condition at the reactive front, possibly due to slow electron transfer from ITO to the polymer matrix, or more likely arising from the resistance to redox propagation in the polymer matrix. On the other hand, oxidation and reduction peak heights scale linearly with

(16) (a) Gaupp, C. L.; Welsh, D. M.; Rauh, R. D.; Reynolds, J . R Chem. Mater. 2002, 14, 3964. (b) Delongchamp, D. M.; Kastantin, M.; Hammond, P. T. Chem. Mater. 2003, 15, 1575. (c) Meng, H.; Tucker, D.; Chaffins, S.; Chen, Y.; Helgeson, R.; Dunn, B.; Wudl, F. Adv. Mater. 2003, 15, 146. (d) Bach, U.; Corr,. D.; Lupo, D.; Pichot, F.; Ryan, M. Adv. Mater. 2002, 14, 845. (e) Cutler, C. A.; Bouguettaya, M.; Reynolds, J . R. Adv. Mater. 2002, 14, 684. (f) Reeves, B. D.; Thompson, B. C.; Abboud, K. A.; Smart, B. E.; Reynolds, J. R. Adv. Mater. 2002, 12, 717. (g) Somani, P. R.; Radhakrishnan, S. Mater. Chem. Phys. 2002, 77, 117. (h) Schwendeman, I.; Hickman, R.; Sönmez, G.; Schottland, P.; Zong, K.; Welsh, D. M.; Reynolds, J. R. Chem. Mater. 2002, 14, 3118. (i) Boehme, J. L.; Mudigonda, D. S. K.; Ferraris, J. P. Chem. Mater. 2001, 13, 4469. (j) Thompson, B. C.; Schottland, P.; Zong, K.; Reynolds, J. R. Chem. Mater. 2000, 12, 1563. (k) Mudigonda, D. S. K.; Boehme, J. L.; Brotherston, I. D.; Meeker, D. L.; Ferraris, J . P. Chem. Mater. 2000, 12, 1508. (I) Gaupp, C. L.; Zong, K.; Schottland, P. Thompson, B. C.; Thomas, C. A.; Reynolds, J. R. Macromolecules 2000, 33, 1132. (m) Welsh, D. M.; Kumar, A.; Meijer, E. W.; Reynolds, J . R. Adv. Mater. 1999, 11, 1379. 


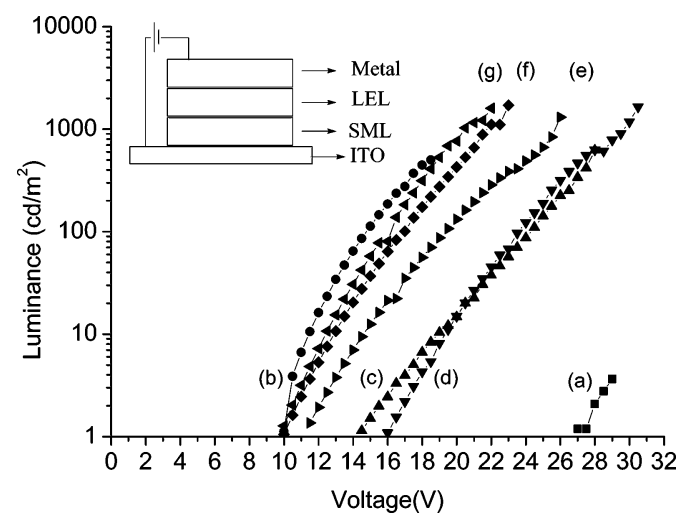

Figure 5. Luminance-voltage characteristic of the lightemitting devices (a) ITO/LEL/AI, (b) ITO/PEDOT/LEL/AI, (c) ITO/3/LEL/AI, (d) ITO/PVK/LEL/AI, (e) ITO/PVK+3/LEL/AI, (f) ITO/PVK+3/LEL/Mg-Ag, and (g) ITO/PVK+2/LE L/MgAg. LEL (light-emitting layer)/PVK/Alq $/$ /Coumarin $6=100$ : 25:0.2 (mg) in $7.6 \mathrm{~mL}$ of $\mathrm{CHCl}_{3}$. SML: surface modification layer. PEDOT: poly(3,4-ethylenedioxythiophene). The inset shows the structure of the devices.

the scan rate, suggesting that the counterion diffusion in the film is reasonably fast. ${ }^{16 \mathrm{~b}}$ In other words, the polymer matrix formed el ectrochemically from $\mathbf{3}$ would be relatively porous and have an open, ion-permeable morphology.

PLED Application. To eval uate the possibility and performance of using the electrochemically deposited thin film on ITO as the surface modification layer, we selected a device of ITO/modification layer/PVK - $\mathrm{Alq}_{3}-$ coumarin 6/metal electrode as a standard device structure for comparison. ${ }^{17}$ Their brightness-voltage relationships are shown in Figure 5.

Without any surface modification, the PLED device showed a high turn-on voltage at $27 \mathrm{~V}$ (line a). In contrast, the introduction of a commercially available PEDOT 18 as a hole-injection layer onto the ITO surface significantly reduced the turn-on voltage to $10 \mathrm{~V}$ (line b), indicating that the hole-injection process is one of the major factors for the device performance. On the other hand, work function of the metal el ectrode is less important in this case. Changing the metal electrode from $\mathrm{Al}$ to $\mathrm{Mg} / \mathrm{Ag}$ did not further improve the turn-on voltage significantly. Electrochemical deposition of $\mathbf{3}$ as a hole-injection layer led to an improvement of the turnon voltage to $14 \mathrm{~V}$ (line c). However, the surface uniformity of the electrochemically deposited thin-film is relatively poor. Although good film was obtained from electrochemical deposition of PVK, ${ }^{5}$ the improvement of the turn-on voltage to $16 \mathrm{~V}$ (line d) is limited by the high ionization potential of the carbazole unit. In contrast, doping of $\mathbf{3}$ into PVK by electrochemical codeposition led to a good quality polymeric film with a thickness of $80 \mathrm{~nm}$. A dramatic drop of the device turnon vol tage to $11.5 \mathrm{~V}$ was found (line e), using Al as the el ectrode. In addition, changing the metal el ectrode from

(17) (a) Kido, J .; Hongawa, K.; Okuyama, K.; Nagai, K. Appl. Phys. Lett. 1994, 64, 815. (b) Osaka, T.; Komaba, S.-i.; Fujihana, K.; Okamoto, N.; Kaneko, N. Chem. Lett. 1995, 1023. (c) Allegrini, M.; Arena, A. Girlanda, R.; Pace, C.; Patanè, S.; Saitta, G. J . Mater. Res. 1999, 14, 2640.

(18) (a) Cao, Y.: Yu, G.; Zhang, C.: Menon, R.; Heeger, A.J. Synth Met. 1997, 87, 171. (b) Brown, T. M.; Kim, J . S.; Friend, R. H.; Calcialli, F.; Daik, R.; Feast, W. J . Appl. Phys. Lett. 1999, 75, 1679. (c) Ho, P. K. H.; Kim, J .-S.; Burroughes, J . H.; Beacker, H.; Li, S. F. Y.; Brown, T. M.; Cacialli, F.; Friend, R. H. Nature (London) 2000, 404, 481.

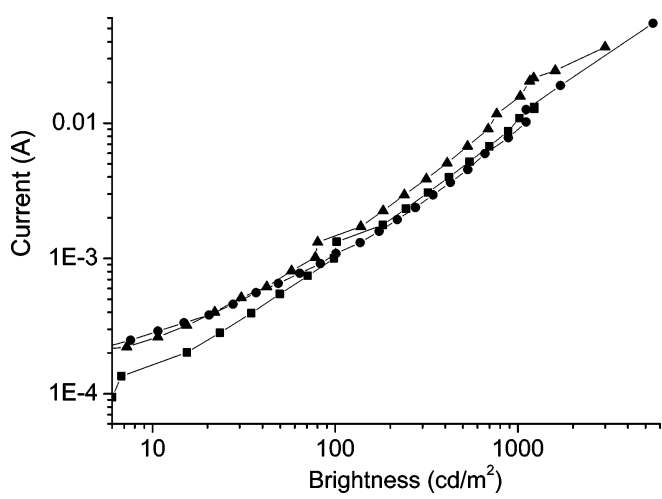

Figure 6. Current and brightness characteristics of the PLED

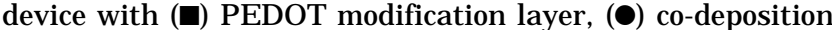
of $\mathbf{3}$ and PVK modification layer, and ( $\mathbf{\Delta}$ ) co-deposition of $\mathbf{2}$ and PVK modification layer.

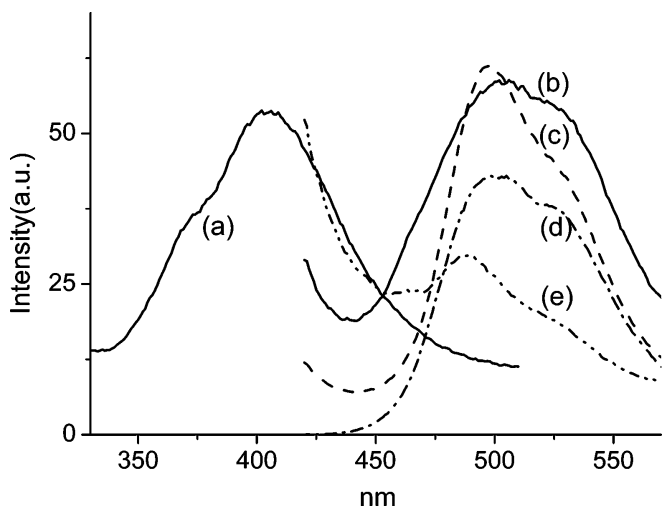

Figure 7. Photoluminescence $(P L)$ and electroluminscence (EL) on ITO glass: (a) PL of PVK; (b) PL of PVK/Ala 3 ; (c) PL of PVK/Alq 3 /coumarin 6; (d) $E L$ of the above device based on PVK+3 SML/PVK-Alq 3 -coumarin 6/Mg-Ag; (e) PL of PVK/ coumarin 6

Al to $\mathrm{Mg} / \mathrm{Ag}$ further improved the turn-on voltage to 10 $V$ (lines $f$ and g). The highest brightness of $2000 \mathrm{~cd} / \mathrm{m}^{2}$ was obtained from this device. We tentatively attribute the low turn-on vol tage to the lower oxidation potential of the starburst triarylamine unit, which is beneficial for the hole-injection process. Similar phenomena have been widely explored in the related PLED and OLED literature. ${ }^{19}$ Although introduction of the el ectrochemical modification layer would be beneficial for the hole injection process, we believe that it does not significantly alter the mechanism for electrolumi nescence. Figure 6 shows the brightness-current characteristics for the devices of ITO/PEDOT/LEL/Mg-Ag, ITO/PVK-2/LEL/ $\mathrm{Mg}-\mathrm{Ag}$, and ITO/PVK-3/LEL/Mg-Ag. All three devices provided similar brightness-current behavior, indicating that similar electron-photon conversion mechanisms are operating in these devices. Figure 7 shows the photoluminescence spectra of PVK, PVK/Alq 3 , PVK/ coumarin 6, PVK/Alq $3 /$ coumarin 6, and el ectrol uminescence $(E L)$ spectrum of the device of PVK +3 SML/PVK $\mathrm{Alq}_{3}$-coumarin 6/Mg-Ag for comparison. The emission spectrum of the $E L$ device peaked at $500 \mathrm{~nm}$ with a

(19) (a) Zhou, X.; Pfeiffer, M.; Blochwitz, J .; Werner, A.; Nollau, A.; Fritz, T.; Leo, K Appl. Phys. Lett. 2001, 78, 410. (b) Giebeler, C.; Antoniadis, H.; Bradley, D. D. C.; Shirota, Y. Appl. Phys. Lett. 1998 72, 2448 (c) Giebeler, C.; Antoniadis, H.; Bradley, D. D. C.; Shirota, Y. J . Appl. Phys. 1999, 85, 608. (d) Carter, S. A.; Angel opoul os, M.; Karg S.; Brock, P. J .; Scott, J . C. Appl. Phys. Lett. 1997, 70, 2067. (e) Yang, Y.; Heeger, A. J . Appl. Phys. Lett. 1994, 64, 1245. 


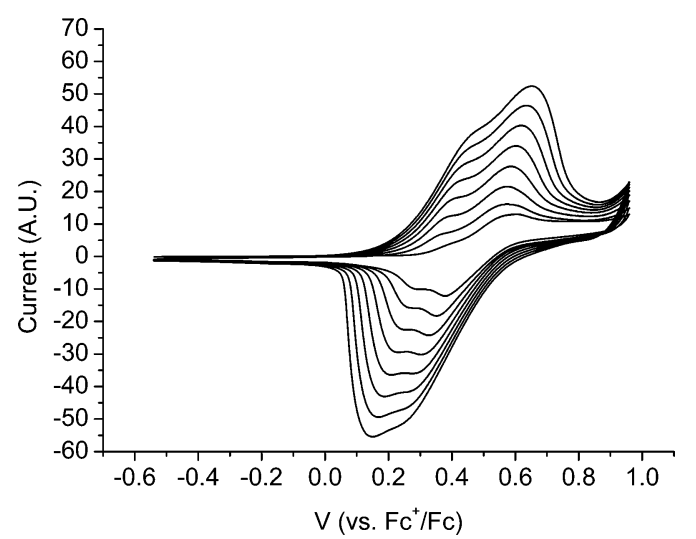

Figure 8. Cyclic voltammogram of compound $\mathbf{3}$ and $\mathrm{PVK}$ in $\mathrm{CH}_{2} \mathrm{Cl}_{2}$ with $(\mathrm{Bu})_{4} \mathrm{NClO}_{4}(0.1 \mathrm{M})$ as the supporting electrolyte.

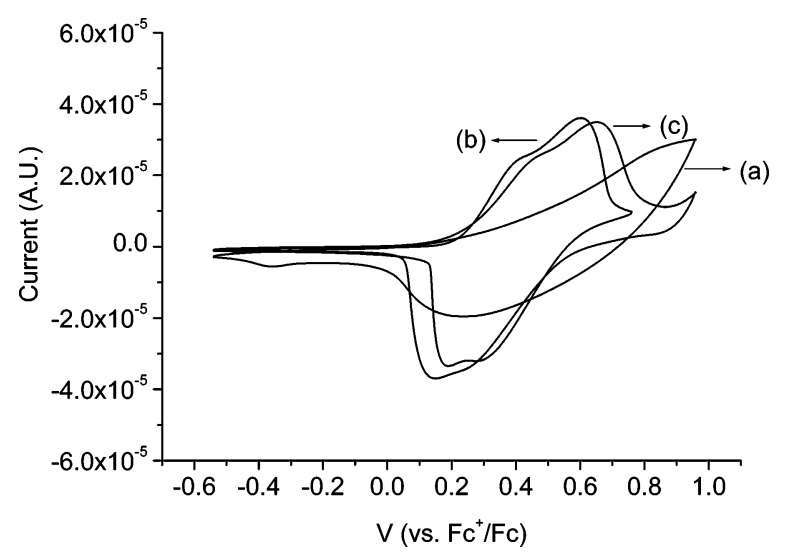

Figure 9. Comparison of the final CV cycles of (a) PVK, (b) $\mathbf{3}$, and (c) a mixture of compound $\mathbf{3}$ and PVK.

shoulder at $525 \mathrm{~nm}$ that mainly arises from $\mathrm{Alq}_{3} /$ coumarin 6. The emission mechanisms of the $\mathrm{Alq}_{3} /$ coumarin 6 system have been discussed in previous literature. ${ }^{20}$

It has long been known that electrochemical deposition of PVK would form thin film with good quality. In our study, we monitored the electrochemical co-deposition process of $\mathbf{3}$ with PVK by $\mathrm{CV}$ and the diagrams are shown in Figure 8. The first scan showed an oxidation profile similar to that of $\mathbf{3}$, along with film growing on the electrode in repeated scans. This observation suggested that oxidation of $\mathbf{3}$ is important in the initiation of the co-deposition process. On the other hand, the CV profile of the final polymeric film was found to be different from either the pure thin film of $\mathbf{3}$ or that of PVK (Figure 9). The $E_{p a}$ and $E_{p c}$ of the co-deposited film are slightly shifted in comparison to those of pure film of $\mathbf{3}$ or PVK. This observation is consistent with the assumption that co-deposition occurs during electrochemical oxidation. However, the redox behavior of the final co-deposited film is somewhat similar to that of $\mathbf{3}$ rather than that of PVK, implying that the weight of $\mathbf{3}$ in the film is significantly high. Since triarylamine derivatives are known to be effective hole-transporting materials, this layer may also function as a holetransporting layer in the $\mathrm{EL}$ device.

To have a physical picture of the morphology of the co-deposited thin film, film from electrochemical co-

(20) (a) Tang, C. W.; VanSlyke, S. A.; Chen, C. H. J . Appl. Phys. 1989, 65, 3610. (b) Kido, J .; I izumi, Y. Appl. Phys. Lett. 1998, 73, 2721.
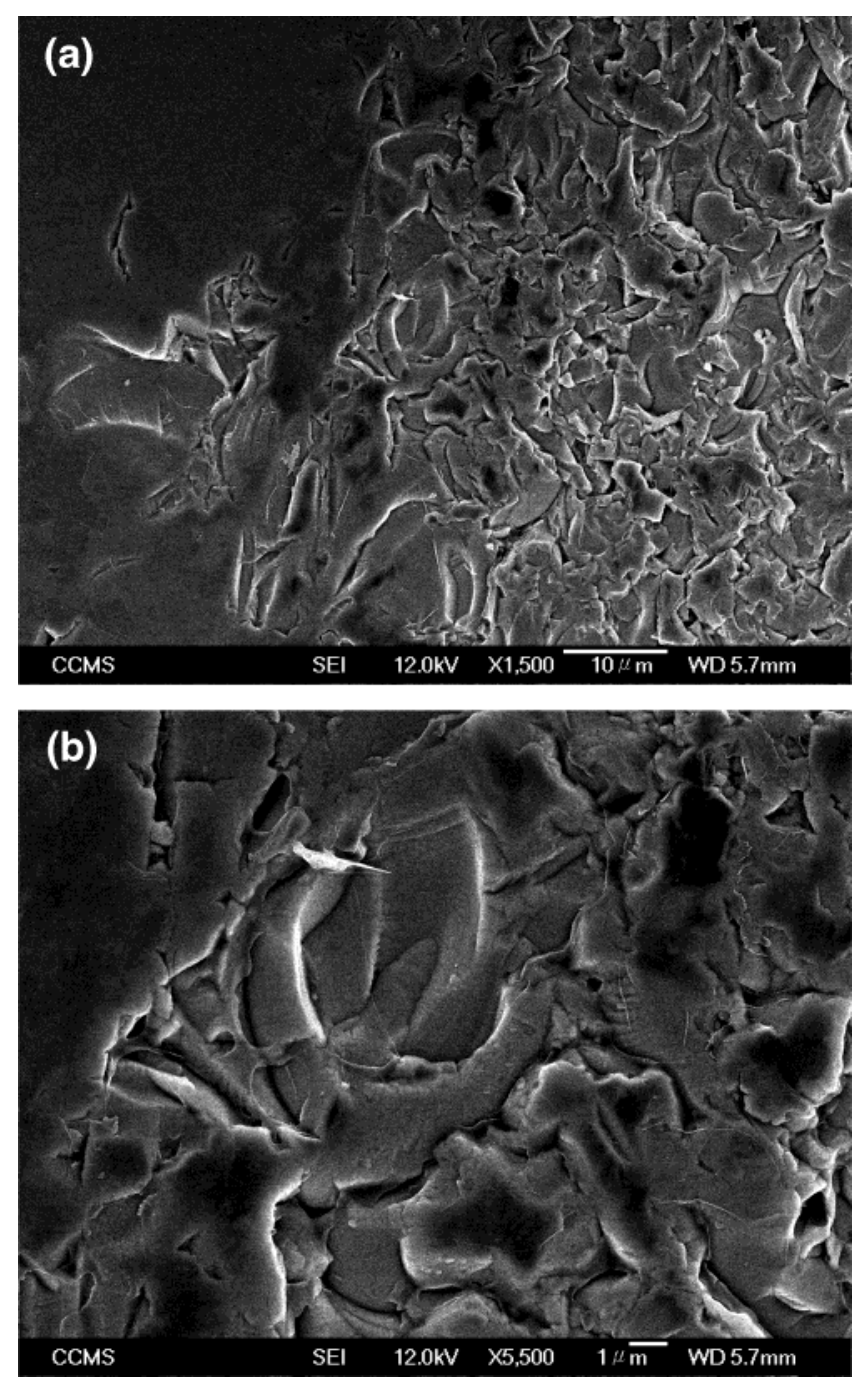

Figure 10. SEM pictures of thin film from electrochemical co-deposition of $\mathbf{3}$ and PVK: (a) morphology of the surface, and (b) close-up of the central area.

deposition of $\mathbf{3}$ and PVK was subjected to scanning electron microscopy (SEM) analysis. The SEM photographs are shown in Figure 10a and b. The bottom picture, Figure 10b, is an enlargement of the central area of Figure 10a. In Figure 10a, a smooth surface shown on the left represents the major part of the surface while a rough surface on the right let us clearly see the amorphous morphology of the film.

In summary, our results provided a convenient way to fabricate thin films of electroactive starburst triarylamine polymers. Research of this electropol ymerization technique to other optoelectronic devices is ongoing.

\section{Experimental Section}

Procedures for Electropolymerization. Electropolymerization of monomers $\mathbf{2}$ and $\mathbf{3}(1 \mathrm{mM})$ was carried out by using the $\mathrm{CV}$ method $(0-1.5 \mathrm{~V}, 100 \mathrm{mV} / \mathrm{sec})$ in $\mathrm{CH}_{2} \mathrm{Cl}_{2}$, using $\mathrm{Bu}_{4}-$ $\mathrm{NClO}_{4}(0.1 \mathrm{M})$ or $\mathrm{Bu}_{4} \mathrm{NPF}_{6}(0.1 \mathrm{M})$ as the supporting electroIyte. The polymeric film was obtained on an ITO glass or Pt working electrode, with a Pt wire as the counter el ectrode, and a $\mathrm{Ag} / \mathrm{AgCl}$ (saturated) electrode as the reference electrode.

Fabrication of Electrochromic Devices. An ITO glass electrode was used as the working electrode. A layer of polymer $\mathbf{2}$ or $\mathbf{3}$ was deposited onto the ITO el ectrode according to the 
above procedure. After polymerization, the film obtained was washed with $\mathrm{CH}_{2} \mathrm{Cl}_{2}$. The electrode was then inserted into a solution of $\mathrm{Bu}_{4} \mathrm{NClO}_{4}(0.2 \mathrm{M})$ in $\mathrm{CH}_{2} \mathrm{Cl}_{2}$. The electrochromism experiments were carried out with applied vol tages from 0 to $1.3 \mathrm{~V}$ with respect to a $\mathrm{Ag} / \mathrm{AgCl}$ (saturated) reference electrode, and their corresponding UV-Vis-NIR absorption spectra were recorded by a J asco V-570 spectrometer.

Fabrication of PLED Devices. To fabricate the PLED, a layer of electropolymerized film was deposited onto ITO glass ( $<20 \Omega /$ sq, Merck Display Technologies Ltd., Taiwan) according to the above procedure. The concentrations of $\mathbf{2}$ and $\mathbf{3}$ used in the electropolymerization experiments were $1 \mathrm{mM}$. The thickness was $50 \mathrm{~nm}$. In the co-electropolymerization experiment of $\mathbf{2}$ with PVK, a solution of $\mathbf{2}(10 \mathrm{mg})$ and PVK $(5 \mathrm{mg})$ in the supporting el ectrolyte $(10 \mathrm{~mL})$ of TBAP $(0.1 \mathrm{M})$ in $\mathrm{CH}_{2^{-}}$ $\mathrm{Cl}_{2}$ was used. In the co-el ectropol ymerization experiment of $\mathbf{3}$ with PVK, a solution of $\mathbf{3}$ (12 mg) and PVK (5 mg) in the supporting el ectrolyte $(10 \mathrm{~mL})$ of TBAP $(0.1 \mathrm{M})$ in $\mathrm{CH}_{2} \mathrm{Cl}_{2}$ was used. The scan rate was $100 \mathrm{mV} / \mathrm{s}$. The thickness was $80 \mathrm{~nm}$. After electropolymerization, the film was undoped by applying a negative potential of $-0.1 \mathrm{~V}$, washed with $\mathrm{CH}_{2} \mathrm{Cl}_{2}$, and dried at $80{ }^{\circ} \mathrm{C}$ in a vacuum oven for $1 \mathrm{~h}$. The light-emitting layer was spin-coated (4000 rpm, $60 \mathrm{~s}$ ) on the electropolymeric film and dried at $130{ }^{\circ} \mathrm{C}$ for $5 \mathrm{~min}$. The thickness of the emitting layer was $100 \mathrm{~nm}$. Finally, a metal electrode was formed by thermal vapor deposition under vacuum (pressure less than $10^{-5}$ Torr). The conductivity experiment was measured by a Keithley 2100 source meter, and the brightness was recorded by a luminance meter (Minolta LS-100). The thickness and roughness were measured by a surface finish measuring system (Kosaka Laboratory Ltd. Surfcorder 1700 $\alpha$ ).

Synthetic Procedures. Tris(4-bromophenyl)amine (4). To an ice-cooled solution of triphenylamine $(3 \mathrm{~g}, 0.012 \mathrm{~mol}$, in 20 $\mathrm{mL}$ of toluene) was added dropwise NBS solution (6.75 g, 0.038 $\mathrm{mol}$, in $60 \mathrm{~mL}$ of DMF). After the addition, the mixture was stirred for a further $15 \mathrm{~min}$ and the reaction was quenched by addition of water. The product was extracted with $\mathrm{CH}_{2} \mathrm{Cl}_{2}$, dried over anhydrous $\mathrm{MgSO}_{4}$, and concentrated under vacuum. The solid was first recrystallized from hexane, and then recrystallized again from $\mathrm{CH}_{3} \mathrm{CN}$ and $\mathrm{EtOH}$ to give $\mathbf{4}(2.65 \mathrm{~g}$ $45 \%)$ as a white solid. ${ }^{1} \mathrm{H}$ NMR $\left(300 \mathrm{MHz} \mathrm{CDCl}_{3}\right): \delta 7.33(\mathrm{~d}$ $J=8.8 \mathrm{~Hz}, 6 \mathrm{H}), 6.90(\mathrm{~d}, \mathrm{~J}=8.8 \mathrm{~Hz}, 6 \mathrm{H}) \cdot{ }^{13} \mathrm{C} \mathrm{NMR}(100 \mathrm{MHz}$ $\left.\mathrm{CDCl}_{3}\right): \delta 146.3,132.8,125.9,116.3$. HRMS-FAB calcd for $\mathrm{C}_{18} \mathrm{H}_{12} \mathrm{~N}^{79} \mathrm{Br}^{81} \mathrm{Br}_{2}$, 482.8479; found, 482.8474. Calcd for $\mathrm{C}_{18} \mathrm{H}_{12-}$ $\mathrm{N}^{79} \mathrm{Br}_{2}{ }^{81} \mathrm{Br}$, 480.8499; found, 480.8500 .

(4-Bromophenyl)diphenylamine (5). A stirred solution of 1,4dibromobenzene $(3.49 \mathrm{~g}, 14.8 \mathrm{mmol})$, diphenylamine $(1.0 \mathrm{~g}, 5.9$ $\mathrm{mmol}$ ), $\mathrm{Pd}_{2}(\mathrm{dba})_{3}(245 \mathrm{mg}, 0.2 \mathrm{mmol}$ ), dppf (198 mg, $0.4 \mathrm{mmol}$ ), and $\mathrm{Na}^{\mathrm{t} O B u}(683 \mathrm{mg}, 7.1 \mathrm{mmol})$ in tol uene $(6 \mathrm{~mL})$ was heated at $90{ }^{\circ} \mathrm{C}$ under $\mathrm{Ar}$ atmosphere for $48 \mathrm{~h}$. After that, the product solution was collected through filtration, and the remaining solid was then washed with $\mathrm{CH}_{2} \mathrm{Cl}_{2}$. The filtrate was collected, dried over anhydrous $\mathrm{MgSO}_{4}$, and evaporated under vacuum. The crude product was purified by chromatography on silica gel, using hexane/ethyl acetate (19:1) as the eluent to give 5 $(1.4 \mathrm{~g}, 73 \%)$ as a colorless solid. ${ }^{1} \mathrm{H}$ NMR $\left(400 \mathrm{MHz}, \mathrm{CD}_{3}\right.$ $\left.\mathrm{COCD}_{3}\right): \delta 7.40(\mathrm{~d}, \mathrm{~J}=9.0 \mathrm{~Hz}, 2 \mathrm{H}), 7.31(\mathrm{t}, \mathrm{J}=7.4 \mathrm{~Hz}, 4 \mathrm{H})$, $7.07(\mathrm{~m}, 6 \mathrm{H}), 6.94(\mathrm{~d}, \mathrm{~J}=9.0 \mathrm{~Hz}, 2 \mathrm{H}) .{ }^{13} \mathrm{C} N M R(100 \mathrm{MHz}$, $\left.\mathrm{CD}_{3} \mathrm{COCD}_{3}\right): \delta 147.4,147.3,132.1,129.5,124.8,124.5,123.5$, 114.1. HRMS-FAB calcd for $\mathrm{C}_{18} \mathrm{H}_{14} \mathrm{~N}^{81} \mathrm{Br}, 325.0289$; found 325.0291. Calcd for $\mathrm{C}_{18} \mathrm{H}_{14} \mathrm{~N}^{79} \mathrm{Br}$, 323.0310; found, 323.0317.

(4'-Bromobi phenyl-4-yl)diphenylamine (6). A stirred solution of 4,4'-dibromobi phenyl $(5.17 \mathrm{~g}, 17 \mathrm{mmol})$, diphenylamine (1.05 $\mathrm{g}, 6.2 \mathrm{mmol}$ ), $\mathrm{Pd}(\mathrm{OAc})_{2}$ (33 mg, $0.15 \mathrm{mmol}$ ), dppf (85 mg, 0.15 $\mathrm{mmol})$, and $\mathrm{Na} \mathrm{a}^{\mathrm{t}} \mathrm{OBu}(6.0 \mathrm{~g}, 62 \mathrm{mmol})$ in toluene $(15 \mathrm{~mL})$ was heated at $100{ }^{\circ} \mathrm{C}$ under $\mathrm{Ar}$ atmosphere for $24 \mathrm{~h}$. After that, the product solution was collected through filtration, and the remaining solid was then washed with ethyl acteate. The filtrates were collected, dried over anhydrous $\mathrm{MgSO}_{4}$, and evaporated under vacuum. The crude product was purified by chromatography on silica gel, using hexanes/ethyl acetate (95: $1)$ as the eluent to give $6(1.0 \mathrm{~g}, 40 \%)$ as a colorless solid. ${ }^{1} \mathrm{H}$ NMR $\left(\mathrm{CDCl}_{3}\right): \delta 7.53(\mathrm{~d}, \mathrm{~J}=8.6 \mathrm{~Hz}, 2 \mathrm{H}), 7.42$ (two sets of overlaying $\mathrm{d}, \mathrm{J}=8.6 \mathrm{~Hz}, 4 \mathrm{H}), 7.28-7.26(\mathrm{~m}, 4 \mathrm{H}), 7.15-7.12$ $(\mathrm{m}, 6 \mathrm{H}), 7.05(\mathrm{t}, \mathrm{J}=7.4 \mathrm{~Hz}, 2 \mathrm{H}) \cdot{ }^{13} \mathrm{C} \mathrm{NMR}\left(\mathrm{CDCl}_{3}\right): \delta 147.51$, $139.51,133.58,131.78,129.29,128.14,127.52,124.51,124.37$, 123.66, 123.08, 120.87. HRMS-FAB calcd for $\mathrm{C}_{24} \mathrm{H}_{18} \mathrm{BrN}$, 399.0623; found, 399.0629.

4-(Diphenylamino)phenyl boronic Acid (7). To Mg turnings $(12 \mathrm{~g}, 0.5 \mathrm{~mol})$ was added a small portion of $5(2 \mathrm{~g}, 6.17 \mathrm{mmol})$ in THF $(70 \mathrm{~mL})$ to initiate the reaction. After initiation, an additional amount of $\mathbf{5}$ (38 g, $0.12 \mathrm{~mol})$ in THF (180 mL) was added dropwise. After addition, the solution was heated at reflux for $2 \mathrm{~h}$. The solution was then cool ed to $-78{ }^{\circ} \mathrm{C}$ and a solution of trimethylborate $(28 \mathrm{~mL}, 0.37 \mathrm{~mol})$ in THF $(50 \mathrm{~mL})$ was added. After further reaction for $12 \mathrm{~h}$ at room temperature, the reaction was quenched by addition of diluted $\mathrm{HCl}$, and the product was extracted with $\mathrm{CH}_{2} \mathrm{Cl}_{2}$ several times. The collected organic layer was dried over anhydrous $\mathrm{MgSO}_{4}$ and concentrated under vacuum to provide a crude solid which was recrystallized from $\mathrm{CH}_{2} \mathrm{Cl}_{2}$ and $\mathrm{CH}_{3} \mathrm{CN}$ to give 7 as white solid (19.6 g, 57\%), $\mathrm{mp}=228^{\circ} \mathrm{C} .{ }^{1} \mathrm{H}$ NMR $\left(400 \mathrm{MHz}, \mathrm{DMSO}-\mathrm{d}_{6}\right): \delta$ $7.85(\mathrm{~s}, 2 \mathrm{H}), 7.67(\mathrm{~d}, \mathrm{~J}=8.4 \mathrm{~Hz}, 2 \mathrm{H}), 7.29(\mathrm{t}, \mathrm{J}=7.6 \mathrm{~Hz}, 4 \mathrm{H})$, 6.99-7.06 $(\mathrm{m}, 6 \mathrm{H}), 6.88(\mathrm{~d}, \mathrm{~J}=8.4 \mathrm{~Hz}, 2 \mathrm{H}) .{ }^{13} \mathrm{C}$ NMR $(100$ $\left.\mathrm{MHz}, \mathrm{CD}_{3} \mathrm{COCD}_{3}\right): \delta 148.9,147.0,135.4,129.5,124.4,123.3$, 121.3. MS-ESI calcd for [M $+\mathrm{H}^{+}$], 290.1; found, 290.3.

Boronic Ester (8). A solution of $\mathbf{6}(2.05 \mathrm{~g}, 5.1 \mathrm{mmol})$ in THF $(50 \mathrm{~mL})$ was stirred at $-78{ }^{\circ} \mathrm{C}$ under $\mathrm{Ar}$ atmosphere for 10 min. A solution of $n-B u L i$ in hexanes $(5 \mathrm{~mL}, 1.6 \mathrm{M})$ was added, and the solution was stirred for $1 \mathrm{~h}$. After that, 2-isopropoxy4,4,5,5-tetramethyl-[1,3,2]-dioxaborolane ${ }^{21}(2 \mathrm{~mL})$ was added at $-78{ }^{\circ} \mathrm{C}$, and the solution was stirred for a further $16 \mathrm{~h}$ at room temp. When the reaction was completed, water was added to quench the reaction. The product was extracted with toluene. The collected solution was dried over anhydrous $\mathrm{MgSO}_{4}$ and concentrated under vacuum to give a crude solid which was recrystallized from toluene and hexane to give $\mathbf{8}$ $(2.0 \mathrm{~g}, 87 \%)$ as a colorless solid. ${ }^{1} \mathrm{H}$ NMR $\left(400 \mathrm{MHz}, \mathrm{CD}_{3-}\right.$ $\left.\mathrm{COCD}_{3}\right): \delta 7.81(\mathrm{~d}, \mathrm{~J}=8.2 \mathrm{~Hz}, 2 \mathrm{H}), 7.66-7.60(\mathrm{~m}, 4 \mathrm{H}), 7.31$ $(\mathrm{t}, \mathrm{J}=7.5 \mathrm{~Hz} ; 4 \mathrm{H}), 7.11-7.07(\mathrm{~m}, 8 \mathrm{H}), 1.35(\mathrm{~s}, 12 \mathrm{H}) .{ }^{13} \mathrm{C} N M R$ $\left(\mathrm{CD}_{3} \mathrm{COCD}_{3}\right): \delta 148.53,148.48,143.83,136.07,135.26,130.27$, $128.56,126.42,125.32,124.34,124.08,84.45,25.19$. HRMSFAB calcd for $\mathrm{C}_{30} \mathrm{H}_{30} \mathrm{O}_{2} \mathrm{~N}$, 447.2370; found, 447.2373.

Starburst Amine 2. A solution of $\mathbf{4}(0.48 \mathrm{~g}, 1.0 \mathrm{mmol}), \mathbf{7}(0.93$ $\mathrm{g}, 3.2 \mathrm{mmol}), \mathrm{Pd}\left(\mathrm{PPh}_{3}\right)_{4}(60 \mathrm{mg}, 0.05 \mathrm{mmol})$, and $\mathrm{Na}_{2} \mathrm{CO}_{3}(0.44$ $\mathrm{g}, 4.2 \mathrm{mmol})$ in toluene $(1.5 \mathrm{~mL})$ and $\mathrm{H}_{2} \mathrm{O}(1 \mathrm{~mL})$ was heated at $110{ }^{\circ} \mathrm{C}$ under $\mathrm{Ar}$ atmosphere for $12 \mathrm{~h}$. When the reaction was completed, water was added to quench the reaction. The product was extracted with $\mathrm{CH}_{2} \mathrm{Cl}_{2}$. The organic layer was collected, dried over anhydrous $\mathrm{MgSO}_{4}$, and evaporated under vacuum. The crude product was purified by chromatography on silica gel, using hexanes/ $\mathrm{CH}_{2} \mathrm{Cl}_{2}(4 / 1)$ as the eluent to give $2(0.30 \mathrm{~g}, 31 \%)$ as a solid. ${ }^{1} \mathrm{H}$ NMR $\left(400 \mathrm{MHz}^{\mathrm{C}} \mathrm{CDCl}_{3}\right): \delta 7.49$ $(\mathrm{d}, \mathrm{J}=8.4 \mathrm{~Hz}, 6 \mathrm{H}), 7.47(\mathrm{~d}, \mathrm{~J}=8.4 \mathrm{~Hz}, 6 \mathrm{H}), 7.27(\mathrm{t}, \mathrm{J}=8.4$ $\mathrm{Hz}, 12 \mathrm{H}), 7.21(\mathrm{~d}, \mathrm{~J}=8.6 \mathrm{~Hz}, 6 \mathrm{H}), 7.15-7.13(\mathrm{~m}, 18 \mathrm{H}), 7.03$ $(\mathrm{t}, \mathrm{J}=7.3 \mathrm{~Hz}, 6 \mathrm{H}) \cdot{ }^{13} \mathrm{C} N M R\left(100 \mathrm{MHz}, \mathrm{CDCl}_{3}\right): \delta 147.72$, $146.80,146.45,135.07,134.68,129.25,127.37,127.31,124.37$, 124.33, 124.06, 122.84. HRMS-FAB calcd for $\mathrm{C}_{72} \mathrm{H}_{54} \mathrm{~N}_{4}$, 974.4348; found, 974.4339 .

Starburst Amine 3. A solution of $4(0.68 \mathrm{~g}, 1.41 \mathrm{mmol}), 8$ $(2.07 \mathrm{~g}, 4.63 \mathrm{mmol}), \mathrm{Pd}\left(\mathrm{PPh}_{3}\right)_{4}(150 \mathrm{mg}, 0.13 \mathrm{mmol})$, and $\mathrm{Na}_{2-}$ $\mathrm{CO}_{3}(0.63 \mathrm{~g}, 5.9 \mathrm{mmol})$ in toluene $(15 \mathrm{~mL})$ and $\mathrm{H}_{2} \mathrm{O}(7.5 \mathrm{~mL})$ was heated at $110^{\circ} \mathrm{C}$ under $\mathrm{Ar}$ atmosphere for $24 \mathrm{~h}$. When the reaction was completed, water was added to quench the reaction. The product was extracted with $\mathrm{CHCl}_{3}$. The organic layer was collected, dried over anhydrous $\mathrm{MgSO}_{4}$, and evaporated under vacuum. The crude product was purified by chromatography on silica gel, using hex $/ \mathrm{CH}_{2} \mathrm{Cl}_{2}$ (3:1) as the eluent to give $3(0.72 \mathrm{~g}, 42 \%)$ as a light yellow solid. ${ }^{1} \mathrm{H}$ NMR $\left(400 \mathrm{MHz} \mathrm{CDCl}_{3}\right): \delta 7.66(\mathrm{~s}, 12 \mathrm{H}), 7.59(\mathrm{~d}, \mathrm{~J}=8.5 \mathrm{~Hz}, 6 \mathrm{H})$, $7.55(\mathrm{~d}, \mathrm{~J}=8.5 \mathrm{~Hz}, 6 \mathrm{H}), 7.32-7.26(\mathrm{~m}, 18 \mathrm{H}), 7.18-7.16(\mathrm{~m}$, $18 \mathrm{H}), 7.06(\mathrm{t}, \mathrm{J}=7.3 \mathrm{~Hz}, 6 \mathrm{H}) .{ }^{13} \mathrm{C} \mathrm{NMR}\left(100 \mathrm{MHz} \mathrm{CDCl}_{3}\right): \delta$ $147.64,147.18,146.76,139.07,138.87,135.06,134.47,129.27$, $127.70,127.55,126.93,126.92,124.43,123.87,122.93 . \mathrm{MS}-$ FAB calcd for $\mathrm{C}_{90} \mathrm{H}_{67} \mathrm{~N}_{4}, 1203.53$; found, 1203.53. Calcd for 819.

21) Pinacol, V.; Mehrotra, R. C.; Srivastava, G. J . Chem. Soc. 1962 
$\mathrm{C}_{90} \mathrm{H}_{66} \mathrm{~N}_{4}, 1202.53$; found, 1202.45. Anal. Calcd $\mathrm{C}_{90} \mathrm{H}_{67} \mathrm{~N}_{4}:$ C, 89.82; H, 5.53; N, 4.66. Found: C, 89.39; H, 5.37; N, 4.45.

Acknowledgment. We thank the National Science Council of the Republic of China, Ministry of Education, and Ministry of Economy for financial support.
Supporting Information Available: ${ }^{1 \mathrm{H}}$ and ${ }^{13} \mathrm{C}$ NMR spectra of $\mathbf{5}, \mathbf{6}, \mathbf{7}, \mathbf{8}, \mathbf{2}$, and $\mathbf{3}$ (pdf, $12 \mathrm{pp}$ ). This material is available free of charge via the Internet at http://pubs.acs.org.

CM034735P 